\title{
GREGORIO CASELA, UN CONSTRUCTOR MEXICANO DE ÓRGANOS DE FINES DEL SIGLO XVIII
}

\section{Michael Drewes}

La historia de los órganos tubulares antiguos de México, de su evolución y de su manufactura aún no ha sido escrita. Hasta la fecha se conocen pocos nombres de organeros que se han destacado en la confección de estos nobles instrumentos musicales, como el famoso José de Nasarre, a quien se le debe uno de los grandes órganos de la Catedral Metropolitana de la ciudad de México, fechado en 1735 , y el del templo obispal de Morelia, del cual queda únicamente la caja, mientras que los mecanismos o "secretos" son de factura reciente. Se sabe que un organero procedente de Ixmiquilpan, José Antonio Sánchez, en 1806, y luego Manuel Suárez, en 1852, remozaron el órgano de la parroquia de Santa Prisca en Taxco, pero se desconoce el autor de este instrumento dieciochesco. Existe en la República Mexicana una asombrosa cantidad de órganos tubulares barrocos que sin lugar a duda han sido fabricados en el país por artesanos locales, y lo más notable de esta circunstancia es que no sólo se trata de instrumentos de la época colonial sino también de aquella de la Independencia y de tiempos posteriores, instrumentos que demuestran que aun habiendo fenecido el viryeinato hubo apego a la tradición organera colonial hispánica hasta, incluso, los primeros decenios de nuestro siglo.

Puede valorarse como verdaderamente venturoso el hecho de haberse restaurado los dos grandes órganos tubulares de 1695 y de 1735 de la Catedral Metropolitana de la ciudad de México, ya que en la actualidad disponemos de estos magníficos testigos revividos de un glorioso pasado musical. El hecho de haber sido restaurados y restituidos a su funcionamiento original puede calificarse como una suerte, también por haberse encontrado en estos instrumentos documentos importantes durante la fase de desmontaje e inventario de las piezas para su envió a Holanda, para efectos de la restauración. Dichos papeles, propiedad del Instituto Nacional de Antropología e Historia, se guardan actualmente en las oficinas de la Dirección de Restauración de Inmuebles Federales de la Secretaría de Asentamientos Humanos y Obras Públicas, para su estudio y evaluación. Algunos de estos documentos tratan de asuntos religiosos; otros, de recetas médicas; incluso se utilizaron páginas de libros enteros para impermeabilizar las flautas grandes de madera, los ductos de viento 
y las cajas de válvulas contra fugas de aire. Tal es el caso de las hojas arrancadas a un tomo sobre instructivos para realizar censos, ${ }^{1}$ redactado en latín.

Hasta ahora poco puede decirse del organero Gregorio Cosela, quien al parecer estuvo activo a fines del siglo xviII. Un documento encontrado revela que era originario y vecino de la ciudad de México, y que se comprometió a manufacturar, bajo la colaboración de los habitantes del pueblo, un órgano para la localidad de Mexicaltongo. En este contrato, el instrumento se denomina "flautado", término generalmente aplicado al registro principal básico, y por "mixturas" habrán de entenderse, en este caso, cualesquiera registros y no necesariamente un registro que se compone de varias hileras de flautas, lo que sería la acepción actual del vocablo. Este contrato de construcción del órgano deja incluso entrever las características del instrumento: de cuatro registros, tanto del lado del bajo como de aquel del triple, ámbito de cuatro octavas en cuarenta $y$ cinco teclas, probablemente del M12 al DO6. La tesitura supuesta resulta del hecho de que en dados casos se le proveía al lado del bajo con menos teclas, para así ahorrarse las flautas más grandes y, por tanto, reducir el costo de la manufactura. También puede suponerse una tesitura del DO2 al SI5, pero entonces en la región más grave del bajo habría una octava corta; es decir: sin las teclas del DO\#2 y del RE\#2. Tal vez pudo haberse tratado de un órgano pequeño en forma de armario, como solían usarse para acompañar los coros. El documento incluye además, al calce, un calendario de pagos, con lo cual se asemeja a la forma que se usa aún hoy en día para contratar la manufactura de un órgano:

México y noviembre de 1760 años.

Digo yo, don Gregorio Casela, maestro de órganos, naturales y vecino de Ia ciudad de México, que por esta obligación presente me hago cargo, y me obligo a entregar un flautado, para el pueblo de Mexicaltongo, conchabado y ajustado con los hijos de dicho pueblo y adjunto con el reverendo presbitero maestro fray padre, en darlo en trescientos y cincuenta pesos y el órgano viejo; quienes dichos hijos con el reverendo presbítero se obligan también a la correspondencia de dicho dinero y órgano, y yo a la del dicho flautado el que se compone de cuatro mixturas en mano derecha, y cuatro en mano izquierda, cuatro octavas, que componen cuarenta y cinco teclas, pájaros y tambor. De cedro de La Habana toda su caja, acondicionada de dar y fluir.

1 Doc. /503-66a. Liber continens omnia, quae necessaria sunt in census creatione. Doc. /503-64a. Secundi tomi de censibus. 
$\mathrm{Y}$ para que este presente papel sirva de obligación, así a la entrega del dicho flautado como de la satisfacción a su valor, apunto al talón lo que fío, bajo de la firma que otorgo hoy 9 de noviembre de 1760 .

Gregorio Casela.

En 9 de noviembre de 60 años. Recibí 31 pesos, 4 reales 31p $4 \mathrm{r}$ Casela.

En 2 de diciembre recibí dieciocho pesos, cuatro reales $18 \mathrm{p} 4 \mathrm{r}$ Casela.

En 23 de diciembre de 60 años recibí cien pesos $100 \mathrm{p} 0 \mathrm{r}$.

En 25 de enero recibí treinta pesos Casela. $30 \mathrm{p}$.

En ? de abril recibí diez pesos y seis reales $10 \mathrm{p} 6 \mathrm{r}$.

Otro documento hallado es interesante porque se trata de un contrato de reparación y modernización del órgano del templo de Nuestra Señora de Balvanera, ubicado en las calles de Uruguay, 132 y Correo Mayor, de la ciudad de México, ${ }^{2}$ cuyas portadas fueron labradas de 1663 a 1671. 3 Así quedó demostrado que dicha iglesia tuvo durante el siglo xvirl un órgano, aunque hoy en día no se halla vestigio ninguno. Este contrato podría asociarse con nuestro organero Gregorio Casela si lamentablemente no le faltara la firma. Aquí vale lo mismo que ya habíamos dicho para el caso anterior: por la palabra "mixtura" simplemente habrá de entenderse un registro cualquiera, sin que necesariamente se trate de uno de varios órdenes de flautas, de acuerdo con el sentido moderno del término. El "flautado mayor" equivale al principal de 8 ' de los órganos europeos, la "espigueta" es un registro flautado tipo Rohrflöte o roerfluit de 4 '. La "docena" es un registro txanspositor a la quinta, de 22/3'; la "quincena", la doble octava, de 2'; y la "diez y setena", la tercera, de $13 / 5$ '. La "octava" corresponde al 4', y el sonido fundamental, al 8' . El epíteto “claro” indica la escala ancha de las flautas, en oposición al "nasardo", que es la mensura angosta. "clarín claro" y "bajoncillo" eran registros de lengüeta, es decir, de trompetería, con un sonido fuerte y hasta estridente. Los "pajaritos" consistian en varias flautas pequeñas sumergidas en un recipiente de agua, con lo que al soplarse imitaban el gorjeo de los pájaros, y los "tambores" se constituían por dos flautas ligexamente desafinadas una con respecto a la otra, que sonaban simultáneamente A continuación, el texto del documento: ${ }^{4}$

2 Expediente núm. 21907 de la Dirección General de Bienes Inmaebles de la Secretaría de Asentamientos Humanos y Obras Públicas.

3 Angulo Iñiguez, Diego Historia del arte hispanoamericano, t. II. Salvat Editores, Barcelona-Madrid, 1950, p. 11.

4 Doc. 22a" "-3. 
Memoria de las mixturas y modo de aderezar que necesita el órgano.

Primeramente, el flautado mayor, que en lo que únicamente permanece.

Flautado violón: se han de hacer todas las flautas nuevas.

Espigueta, toda la mixtura nueva.

Octava clara, toda la mixtura nueva.

Docena clara, toda la mixtura nueva.

Quincena clara, toda la mixtura nueva.

Diez y setena, toda la mixtura nueva.

A más de las referidas mixturas, se le ha de añadir lo siguiente:

Una mixtura de clarín claro.

Otra de bajoncillo.

$Y$ en la mano derecha se le han de añadir al secreto tres canales, y por lo consiguiente, tres flautas más en cada mixtura de las arriba expresadas. Los fuelles que están bien maltratados, se han de reformar y elevar más del suelo.

La caja que es de fábrica antigua, se ha de poner con todas sus cornisas y demás follajes a la moderna; los registros y demás compuestos que se habian maltratado, se le han de hacer sus reparos correspondientes, a fin de que todo el órgano quede de dar y recibir; todo lo dicho me obligo a efectuar con la perfección que pide, por la cantidad de ochocientos pesos

Recibí de la muy respetable madre abadesa y del señor mayordomo del convento de Nuestra Señora de Balvanera la cantidad de diez pesos de un tercio cambiado en dos de octubre (en 28 de septiembre) de este presente año, cuya cantidad tengo asignada por la afinación y aderezos menores del órgano de dicho convento, y para que conste, doy éste en México en tres de octubre de 1761 años.

Otra prueba de que el templo de Nuestra Señora de Balvanera contara con un órgano durante el siglo xvIrI, la da un documento por el cual ahora sí podemos constatar con toda certeza la intervención de nuestro organero, ya que se trata de una carta a él dirigida probablemente por una monja del convento que le pide se afinara no sólo el órgano de la iglesia sino también el clavecín de una de las monjas: ${ }^{5}$

Señor Gregorio Casela:

Muy señor mío de toda mi estimación, apréciase mucho que vuestra merced goce muy cabal salud. La mía queda muy a la disposición con la buena voluntad que siempre haya. Nuestro padre mayordomo me dijo el favor que nos hace, lo que en mi corazón le agradezco y siento en él, los alcances del convento por ser ellos motivos de escasez, la cortedad con que mostrába mos nuestro afecto, el que desea todos los alivios de vuestra merced aquí en ésa suplico me haga el gusto de venir a afinarme el órgano, mañana por la mañana, que aunque hay misa cantada es temprano. También quiere Gertrudis que le afine vuestra merced el clave; espero me haga esta honra como siempre.

5 Doc 22a. 1-4. 
Dios guarde la vida de vuestra merced muchos años.

Balvanera y marzo 24 de 1763.

B.

Seguro servidor que le estima

Isabel de la...

Parece que el señor Gregorio Gasela estaba de por sí relacionado con los conventos de monjas, pues subsiste una carta en la cual una monja de aquel de la Concepción, le encarga la hechura de una cajita: ${ }^{6}$

Señor don Gregorio Casela:

Estimado señor mío; Sabiendo el favor de vuestra merced, me atrevo a molestarle para que por el siglo de señora y por vida de los niños quiera hacerme una cajita del mismo palo que esa que remito, con los mismos tamaños y dos llaves, de manera que salgan tan iguales que una de la otra no se distingan. En fin, asi lo espero de sus primores en los que me fío para quedar bien con la señora, que de mi sea fiado por ser persona a quien debo infinitos favores: El conito me avisa vuestra merced para remitírselo, y le encargo que traiga y me remita la cajita, envío por que esta tarde ha de ser.

Deseo servir de su salud la que deseo sea muy cumplida, y que el Señor se la mantenga muchos años.

Convento de la Concepción, abril 17 de 1763 años.

Señor mío:

Beso las manos de vuestra merced, su agradecida servidora

Por su vida de encargo la mayor brevedad.

Ana Francisca de S. S.

Lo solicitado que era nuestro constructor de órganos lo revela una carta que se hallaba pegada en la caja de ecos del registro "corneta de eco" del órgano del lado poniente del coro de la catedral: 7

Señor don Gregorio Casela:

Amigo y señor: He solicitado a vuestra merced en su casa y en el colegio muchas ocasiones, y no le he podido ver. $\mathrm{Y}$ respecto a lo que tenemos que hablar, le suplico me cite la hora en que pueda yo pasar a su casa [ilegible por tinta corrida] ponerme a perder el tiempo que tanto necesito para mis negocios.

Somos 29 de abril de 1762

A vuestra merced con un afec. tísimo abrazo.

Soto Carrillo.

6 Doc 22a 1-9.

7 Doc $22 \mathrm{a} 7$. 
Parece que Gregorio Casela también debe de haber tenido uno o varios hermanos o hermanas, pues un recado lo cita como "hermano": 8

A don Gregorio Casela, mi estimado hermano que Dios guarde muchos años como deseo en

México,

Y otro recado - una de estas breves notas que contienen saludos a cortos mensajes escritos en papeletas o billetdoux, ya que no se disponía de las facilidades de comunicación de hoy día, expresa la estimación en la cual se tuvo a nuestro maestro de órganos: 9

Al señor don Gregorio Casela que Dios, nuestro señor guarde muchos años como deseo, etc. en fuente de las monjas de Santa Clara.

Un recado que en el anverso dice: ${ }^{10}$

Reverendo maestro Casela: Hoy esperé a vuestra merced hasta las nueve y media, conforme quedamos, y vuestra merced me ofreció por lo que en virtud de ser el concierto esta noche, he de deber a vuestra merced no deje de venir esta tarde a templar el clave, de lo que le quedaré muy agradecido y muy servidor:

Rocca.

revela en el reverso aun el domicilio de nuestro maestro constructor de órganos, lo que permite investigar en el archivo parroquial correspon. diente -una vez establecida la equivalencia moderna del nombre de la calle-, al menos la fecha de su muerte:

Ilustrísimo señor Gasela, organero de Ia Santa Iglesia. Vive en el callejón de Santa Clara, junto a un cerrajero.

Hasta aquí lo poco que logramos reunir de Gregorio Casela, un hasta ahora desconocido maestro constructor de órganos mexicano del siglo xvirr. Esperamos que futuras investigaciones atrojen más luz sobre el asunto, y que de esta manera se llegue algún día a completar la historia de la construcción de órganos en México.

8 Doc. $22 a^{, ",}$

1 Doc. 22 a $1-10$

xo Doc, $22 \mathrm{a}-8$ 